\title{
Primary Care Physician Panel Size and Quality of Care: A Population-Based Study in Ontario, Canada
}

\author{
Simone Dabrouge, $\mathrm{PbD}^{1-5}$ \\ William Hogg, MDCM $M^{1,2,3,4}$ \\ Jaime Younger, MSc ${ }^{5,6}$ \\ Elizabeth Muggab, MD ${ }^{1,2}$ \\ Grant Russell, MBBS, FRACGP, $P b D^{7}$ \\ Richard H. Glazier, $M D^{8-11}$ \\ 'Department of Family Medicine, Univer- \\ sity of Ottawa, Canada \\ ${ }^{2}$ C.T. Lamont Primary Health Care \\ Research Centre, Bruyère Research Insti- \\ tute, Ottawa, Canada \\ ${ }^{3}$ Institute of Population Health, University \\ of Ottawa, Canada \\ ${ }^{4}$ Department of Epidemiology and Commu- \\ nity Medicine, University of Ottawa, Canada \\ ${ }^{5}$ Institute of Clinical Evaluative Sciences, \\ Ottawa, Canada \\ ${ }^{6}$ Ottawa Hospital Research Institute, \\ Ottawa, Canada \\ ${ }^{7}$ Southern Academic Primary Care Research \\ Unit. School of Primary Health Care, \\ Monash University, Clayton, Australia \\ ${ }^{8}$ Institute for Clinical Evaluative Sciences, \\ Toronto, Canada \\ ${ }^{9}$ Department of Family and Community \\ Medicine, University of Toronto, Canada \\ ${ }^{10}$ Department of Family and Community \\ Medicine, St. Michael's Hospital, Toronto, \\ Canada \\ ${ }^{11}$ Centre for Research on Inner City Health, \\ St. Michael's Hospital, Toronto, Canada
}

\section{$\operatorname{lin}_{\mathrm{i}}$ \\ MORE ONLINE \\ www.annfammed.org}

Conflicts of interest: authors report none.

\section{CORRESPONDING AUTHOR}

Simone Dahrouge, $\mathrm{PhD}$

C.T. Lamont Primary Health Care Research Centre

Bruyère Research Institute

85 Primrose Ave

Ottawa, Ontario K1R 6M1

Canada

sdahrouge@bruyere.org

\begin{abstract}
PURPOSE The purpose of this study was to determine the relationship between the number of patients under a primary care physician's care (panel size) and primary care quality indicators.
\end{abstract}

METHODS We conducted a cross-sectional, population-based study of fee-forservice and capitated interprofessional and non-interprofessional primary health care practices in Ontario, Canada between April 2008 and March 2010, encompassing 4,195 physicians with panel sizes $\geq 1,200$ serving 8.3 million patients. Data was extracted from multiple linked, health-related administrative databases and covered 16 quality indicators spanning 5 dimensions of care: access, continuity, comprehensiveness, and evidence-based indicators of cancer screening and chronic disease management.

RESULTS The likelihood of being up-to-date on cervical, colorectal, and breast cancer screening showed relative decreases of $7.9 \%(P<.001), 5.9 \%(P=.01)$, and $4.6 \%(P<.001)$, respectively, with increasing panel size (from 1,200 to 3,900 ). Eight chronic care indicators (4 medication-based and 4 screening-based) showed no significant association with panel size. The likelihood of individuals with a new diagnosis of congestive heart failure having an echocardiogram, however, increased by a relative $8.1 \%(P<.001)$ with higher panel size. Increasing panel size was also associated with a $10.8 \%$ relative increase in hospitalization rates for ambulatory-care-sensitive conditions $(P=.04)$ and a $10.8 \%$ decrease in non-urgent emergency department visits $(P=.004)$. Continuity was highest with medium panel sizes $(P<.001)$, and comprehensiveness had a small decrease $(P=.03)$ with increasing panel size.

CONCLUSIONS Increasing panel size was associated with small decreases in cancer screening, continuity, and comprehensiveness, but showed no consistent relationships with chronic disease management or access indicators. We found no panel size threshold above which quality of care suffered.

Ann Fam Med 2016;14:26-33. doi: 10.1370/afm.1864.

\section{INTRODUCTION}

G iven the central role that primary health care plays in creating a sustainable health care system, improving access to high quality primary health care is an international priority. ${ }^{1}$ Where physician resources are scarce, one way to achieve better population coverage and ensure that all individuals have a primary care physician is to promote larger panel sizes, defined as the number of patients under the care of a primary care provider. There is, however, a concern that quality may decline at larger panel sizes. ${ }^{2}$ Establishing the "ideal" panel size for a primary care physician by striking a balance between population access and quality of care is a key objective for decision-makers and clinicians. Setting a maximum size or range, however, is challenging because quality of care can be influenced by a large number of patient, provider, and contextual factors.

Studies have reported significant correlations between larger panel sizes and shorter consultations, ${ }^{3}$ fewer home visits, ${ }^{4,5}$ and higher rates of referral to specialists. ${ }^{6}$ Previous research conducted by members of our 
team has also found an association between higher selfreported panel sizes and lower likelihood of providing high quality primary and secondary preventive care. ${ }^{7-9}$ These findings help to identify potential problems with excessive panel sizes but are insufficient to define optimal panel size ranges.

Our objective was to investigate the relationship between panel size and a comprehensive set of primary care quality indicators using linked, population-based health administrative databases. Our approach was to allow the existing pattern of relationship to emerge, with no a priori assumptions about the shape of that relationship or whether there was a cut-off point across which performance would be compared. Our hypothesis was that the quality of patient care would drop as panel size increased.

\section{METHODS}

We conducted a cross-sectional, population-based study of primary care services from April 1, 2008, to March 31, 2010 in the province of Ontario, Canada. The datasets used were linked using unique, encoded identifiers and analyzed at the Institute for Clinical Evaluative Sciences (ICES), a not-for-profit research institute. The databases used for this purpose are described in Supplemental Appendix 1, available at http://www. annfammed.org/content/14/1/26/suppl/DC1. This study was approved by the Bruyère Research Institute Ethics Board and by the Research Ethics Board at Sunnybrook Health Sciences Centre, Toronto, Canada.

\section{Setting}

Canada has a publicly funded universal health care system. In Ontario, all medically necessary physician, laboratory, and hospital fees are covered by the Ontario Health Insurance Plan (OHIP) for all 13 million permanent residents, and prescription medications are covered for those on social assistance and those who are aged 65 years or older. More than $80 \%$ of Ontarians receive care in 1 of 3 models: reformed feefor-service, capitation/non-interprofessional team, and capitation/interprofessional team. In the fee-for-service model, patient enrollment is strongly encouraged, and physicians accrue a fee for each service they perform. In the capitation model, patient enrollment is an integral component of the compensation in that physicians receive a monthly allotment based on an age-sex adjusted formula for each patient enrolled in their practice. Approximately one-half of these capitated practices were funded by the Ontario Health Ministry to build interprofessional teams. Team composition varies across practices, but teams include non-clinical and clinical staff such as nurses, pharmacists, and social workers who work alongside physicians in the practice. All 3 models offer physicians financial inducements for achieving quality goals. These include payments for achieving various thresholds of cancer screening and immunizations, incentives for completing flow sheets for diabetes and congestive heart failure, and bonus payments for after-hours care.

\section{Participants}

\section{Physicians}

We used the Corporate Provider Database to identify primary care physicians and attribute them to the model in which they were working on March 31, 2010. We limited the evaluation to generalists working in 1 of the 3 primary care models that serve the majority of Ontarians. Physicians were excluded if they were identified as specialists in the Ontario Physician Human Resource Database or were deemed to have a focused practice because they billed OHIP fewer than 8 of the 18 standard primary care fee schedule codes during the study period. Physicians with a prolonged absence from active practice (no billings for at least 8 consecutive weeks during the study period) were also excluded.

We obtained the age, sex, place of residency, training (Canadian and international), number of years since medical school graduation, practice size, number of years of experience working in their current payment model, and practice rurality for each physician from the Corporate Provider Database. Rurality was determined using the Rurality Index of Ontario (RIO) ${ }_{1}^{10}$ which derives its measure from population density and availability of additional health services within the area. RIO ranges from 0 to 100 , with higher numbers indicating greater rurality, and is commonly grouped into 3 categories: major urban (less than 10), urban (10 to 45 ), and rural (greater than 45).

\section{Panel Size}

We defined panel size for each physician as the number of patients receiving their care from that physician. All patients formally enrolled under the care of a physician (86\% of patients) as of March 31, 2010, as identified by the Client Agency Program Enrollment Tables were attributed to that physician's panel. The remaining patients, those not formally enrolled, were virtually rostered to the physician from whom they received the majority of their primary care services during the twoyear study period, as determined by their costs.

Because the amount of time a physician worked in his or her clinic would considerably influence the number of patients for whom the physician would have the capacity to care for, and since we did not have a measure of work hours or full-time equivalent available in the health administrative data, we used small panel 
size as a proxy. We hypothesized that part-time clinicians would be more likely to have smaller panels, and that by excluding physicians with the smaller panel sizes, we would have a more homogeneous population. Because approximately $25 \%$ of primary care physicians in Ontario report working part time, we excluded physicians with panel sizes less than 1,200 patients, which eliminated the lower tertile.

\section{Patients}

We included patients with valid health care coverage (OHIP). Patient age and sex were obtained from the Registered Persons Database. We linked the postal codes to census data using the Postal Code Conversion File to determine residential patient income quintiles. ${ }^{11,12}$ Immigration status was inferred based on when patients were issued their OHIP cards: if prior to 1998 , they were considered long-term residents of the province, and if after 1998, they were considered recent registrants. Approximately $80 \%$ of recent registrants are immigrants from other countries, while the remainder are interprovincial migrants. ${ }^{13}$ To measure patient complexity or burden of disease we used Resource Utilization Bands with a range from 0 to 5 , derived from physician claims and hospital admissions using the Johns Hopkins Adjusted Clinical Groups (ACG) System. ${ }^{14}$ We used the Ontario Diabetes Database, ${ }^{15}$ Congestive Heart Failure registry, ${ }^{16}$ and Ontario Asthma Surveillance Information System ${ }^{17}$ to identify patients with these conditions. These databases are based on validated algorithms with high specificity for the target condition.

\section{Quality of Care Indicators}

We relied on 16 indicators of primary care delivery covering 5 dimensions of care: cancer screening, chronic disease management, access, continuity, and comprehensiveness. Supplemental Appendix 2, available at http://www.annfammed.org/content/14/1/26/ suppl/DC1, provides the operational definition of the indicators and indicates whether financial incentives were available for each measure during the study period. Medication indicators were evaluated only in individuals aged 65 years and older because data were not available for other age groups.

We evaluated access and continuity indicators for all patients. Comprehensiveness was measured at the physician level. Cancer screening and chronic care indicators were evaluated in the subset of patients eligible for that care. For instance, colorectal cancer screening was assessed only in patients aged 50 to 74 years, while eye screening and hemoglobin $\mathrm{A}_{1 \mathrm{c}}$ tests were assessed only in individuals with diabetes and aged 40 years and older.

\section{Analyses}

\section{Statistical Methods}

We conducted multilevel regressions to assess the relationship between panel size and each quality of care indicator, using generalized estimating equations to account for the clustering effect of patients within physicians. Panel size was the main independent variable, with each indicator in turn the dependent variable. We used negative binomial regressions for all indicators with count outcomes (access measures), logistic regressions for indicators of cancer screening and chronic disease management, and linear regressions for continuity and comprehensiveness. Because of the known strong influence of rurality on the use of hospital services, access regression analyses were carried out only for major urban regions $(\mathrm{RIO}<10)$. For all other models, the inclusion of the RIO index in the model was felt to be sufficient to account for any potential influence rurality might have on these indicators. Regressions were adjusted for all factors listed in Table 1 and the primary care model. Statistical significance was set at 0.05 , and $95 \%$ confidence intervals were reported.

We used restricted cubic splines to optimize modeling of the relationship between panel size and each outcome variable. The curving functions of the cubic splines allow the existing pattern of the relationship between panel size and the outcome to emerge. ${ }^{18} \mathrm{We}$ chose to use 3 knots for our analyses after comparing the QICu (a goodness of fit measure) of 3-, 4-, 5 -, and 7-knot splines as applied to our data because the higher knot numbers were unnecessary and overfitted the data. Statistical analyses were performed using SAS version 9.2 statistical software (SAS Institute). Restricted cubic spline regressions were implemented for each outcome with the "\%daspline" SAS macro. ${ }^{19}$ We used the regression coefficients to derive the estimated level of the quality indicator across panel sizes 1,200 to 3,900 , setting the coefficients at their mean or mode, as appropriate.

\section{RESULTS \\ Population}

In total, 6,801 physicians operated in the 3 primary care models during the study period. From this group, 38 were removed due to prolonged absences and 373 because they were deemed to be specialists or primary care physicians with focused practices, leaving 6,390 physicians. Removing physicians with panel sizes less than 1,200 left 4,195 physicians serving a total patient population of 8.3 million people. The practices excluded due to low panel size did not differ markedly from the sample as a whole, with the exception that excluded practices were more likely to care for women 
( $56 \%$ vs $52 \%)$ and be rural (9.1\% vs $3.3 \%)$. We also ensured that quality of care did not peak at panel sizes less than 1,200 by visualizing the relationship in the lower panel sizes (results not shown). Table 1 shows the patient profile across panel sizes. Physicians with larger panel sizes were more likely to be male, foreign trained, and work in urban practices. Immigrant patients and those from lower income quintiles were more likely to receive care from physicians with larger panel sizes.

\section{Adjusted Analyses}

The relationship between panel size (at intervals of 300) and each indicator is shown in Table 2. Plots of the mean estimates of each indicator across panel size and the omnibus $P$ value are displayed in Supplemental Appendix 3, available at http://www.annfammed. org/content/14/1/26/suppl/DC1. The omnibus $P$ value represents the overall effect of the 2 panel-size cubic spline variables produced by the equation.

Table 1. Patient, Physician, and Practice Characteristics Across Panel Size Ranges

\begin{tabular}{|c|c|c|c|c|c|c|}
\hline \multirow[b]{2}{*}{ Characteristic } & \multicolumn{6}{|c|}{ Panel Size } \\
\hline & All & $1,200-1,799$ & $1,800-2,399$ & $2,400-2,999$ & $3,000-3,599$ & $3,600+$ \\
\hline \multicolumn{7}{|l|}{ Physician profile } \\
\hline Physicians, No. & 4,195 & 2,028 & 1,351 & 526 & 168 & 122 \\
\hline Age, median (IQR), y & $53(46-59)$ & $51(44-58)$ & $54(47-60)$ & $55(47-60)$ & $54(47-58)$ & $52(46-58)$ \\
\hline Male, mean $\%$ & 68.9 & 59.9 & 74.7 & 81.7 & 76.8 & 89.3 \\
\hline Foreign trained, mean $\%$ & 26.9 & 22.7 & 27.4 & 34.2 & 41.1 & 39.3 \\
\hline Time since graduation, median (IQR), y & $27(20-34)$ & $25(18-33)$ & $28(21-35)$ & $28(22-35)$ & $28(21-33)$ & $25(19-33)$ \\
\hline Practice group size, median (IQR), No. & $16(7-30)$ & $15(7-30)$ & $16(7-29)$ & $18(7-31)$ & $17(7-36)$ & $18(5-54)$ \\
\hline Rurality: RIO index, median (IQR) & $2(0-8)$ & $2(0-10)$ & $2(0-8)$ & $2(0-6)$ & $2(0-8)$ & $0(0-3)$ \\
\hline \multicolumn{7}{|l|}{ Rurality categories, \% } \\
\hline Major urban (RIO <10) & 76.6 & 74.0 & 77.3 & 81.2 & 79.1 & 89.1 \\
\hline Minor urban (RIO 10-45) & 20.4 & 21.8 & 20.2 & 17.4 & 20.9 & 10.9 \\
\hline Rural $(\mathrm{RIO}>45)$ & 3.0 & 4.2 & 2.5 & 1.4 & 0.0 & 0.0 \\
\hline \multicolumn{7}{|l|}{ Patient profile } \\
\hline Patients, No. & $8,265,930$ & $3,014,806$ & $2,792,387$ & $1,399,485$ & 547,305 & 511,947 \\
\hline Proportion virtually rostered, \% & 12.7 & 13.6 & 11.5 & 12.5 & 13.0 & 13.5 \\
\hline Age, median (IQR) & $41(21-56)$ & $41(22-57)$ & $41(21-57)$ & $40(21-56)$ & $38(20-54)$ & $37(20-52)$ \\
\hline 0 to18 y, \% & 21.5 & 21 & 21.1 & 21.7 & 23 & 23.5 \\
\hline 19 to $<65$ y, \% & 63.9 & 63.4 & 63.7 & 64.3 & 64.9 & 65.9 \\
\hline$\geq 65 y, \%$ & 14.6 & 15.7 & 15.2 & 14.1 & 12.1 & 10.6 \\
\hline Male, \% & 48.3 & 46.4 & 49.0 & 49.6 & 49.1 & 50.6 \\
\hline Recent immigrants, \% & 10.5 & 8.4 & 8.7 & 11.3 & 15.8 & 25.0 \\
\hline Rurality: RIO index, median (IQR) & $2(0-11)$ & $2(0-14)$ & $2(0-11)$ & $2(0-8)$ & $2(0-8)$ & $0(0-5)$ \\
\hline \multicolumn{7}{|l|}{ Rurality categories, \% } \\
\hline Major urban $($ RIO <10) & 73.5 & 70.5 & 72.9 & 76.0 & 76.6 & 84.0 \\
\hline Minor urban (RIO 10-45) & 23.1 & 24.6 & 23.9 & 22.0 & 22.4 & 14.7 \\
\hline Rural $(\mathrm{RIO}>45)$ & 3.4 & 4.9 & 3.2 & 1.0 & 1.0 & 1.2 \\
\hline \multicolumn{7}{|l|}{$\begin{array}{l}\text { Socioeconomic profile by income } \\
\text { quintile (\%) }\end{array}$} \\
\hline First (lowest) & 18.0 & 16.6 & 17.3 & 18.7 & 22.0 & 24.3 \\
\hline Second & 19.6 & 18.6 & 19.4 & 20.4 & 21.1 & 23.0 \\
\hline Third & 20.5 & 19.9 & 20.6 & 21.3 & 20.9 & 21.3 \\
\hline Fourth & 21.6 & 22.4 & 21.8 & 21.0 & 19.8 & 18.4 \\
\hline Fifth (highest) & 20.3 & 22.5 & 20.9 & 18.6 & 16.2 & 13.0 \\
\hline \multicolumn{7}{|l|}{ Case mix: ${ }^{a}$ Resource Utilization Bands (\%) } \\
\hline 0 (lowest) & 13.0 & 12.5 & 13.5 & 13.1 & 13.0 & 13.4 \\
\hline 1 & 10.8 & 10.5 & 10.8 & 11.1 & 11.2 & 11.2 \\
\hline 2 & 27.2 & 27.0 & 27.4 & 27.1 & 27.8 & 27.4 \\
\hline 3 & 40.7 & 41.2 & 40.2 & 40.7 & 40.4 & 40.5 \\
\hline 4 & 6.6 & 6.9 & 6.5 & 6.4 & 6.3 & 6.3 \\
\hline 5 (highest) & 1.7 & 1.8 & 1.7 & 1.6 & 1.4 & 1.3 \\
\hline
\end{tabular}


Table 2. Estimated Performance Level in the Fully Adjusted Model for the Corresponding Panel Size

\begin{tabular}{|c|c|c|c|c|c|c|}
\hline \multirow[b]{2}{*}{ Indicator } & \multirow{2}{*}{$\begin{array}{c}\text { Panel size } \\
P \text { value }\end{array}$} & \multicolumn{5}{|c|}{ Panel Size } \\
\hline & & 1,200 & 1,500 & 1,800 & 2,100 & 2,400 \\
\hline \multicolumn{7}{|c|}{ Cancer screening, \% $(95 \% \mathrm{Cl})$} \\
\hline Breast & $<.001$ & $64.6(63.9-65.3)$ & $64.2(63.8-64.6)$ & $63.8(63.4-64.1)$ & $63.4(63.0-63.8)$ & $63.1(62.6-63.6)$ \\
\hline Cervical & $<.001$ & $63.7(62.9-64.5)$ & $62.8(62.3-63.2)$ & $61.9(61.5-62.3)$ & $61.1(60.5-61.6)$ & $60.4(59.8-61.0)$ \\
\hline Colorectal & .01 & $45.6(44.3-46.8)$ & $44.6(43.9-45.4)$ & $43.8(43.2-44.4)$ & $43.2(42.5-43.9)$ & $42.9(42.1-43.8)$ \\
\hline \multicolumn{7}{|c|}{ Chronic disease management, \% $(95 \% \mathrm{CI})$} \\
\hline \multicolumn{7}{|l|}{ Diabetes } \\
\hline Eye examination & .75 & $71.6(71.1-72.2)$ & $71.8(71.4-72.1)$ & $71.8(71.6-72.1)$ & $71.9(71.6-72.2)$ & $71.9(71.6-72.3)$ \\
\hline Lipid test & .59 & $62.8(61.4-64.1)$ & $63.0(62.2-63.8)$ & $63.1(62.5-63.8)$ & $63.3(62.5-64.1)$ & $63.5(62.6-64.3)$ \\
\hline $\mathrm{HbA}_{1 \mathrm{c}}$ test & .11 & $39.7(38.2-41.2)$ & $39.3(38.5-40.2)$ & $39.0(38.3-39.7)$ & $38.6(37.8-39.5)$ & $38.3(37.3-39.3)$ \\
\hline Metformin & .24 & $89.1(87.0-90.9)$ & $88.5(87.1-89.7)$ & $87.9(86.8-88.8)$ & $87.4(86.2-88.5)$ & $87.0(85.6-88.3)$ \\
\hline ACEi/ARB & .19 & $73.3(72.6-74.0)$ & $73.5(73.1-73.9)$ & $73.7(73.4-74.0)$ & $73.9(73.5-74.3)$ & $74.0(73.5-74.4)$ \\
\hline Lipid-lowering agent & .66 & $69.7(68.8-70.5)$ & $69.8(69.3-70.3)$ & $69.9(69.5-70.3)$ & $70.0(69.5-70.5)$ & $70.1(69.5-70.6)$ \\
\hline \multicolumn{7}{|l|}{ Other } \\
\hline CHF: ECHO & $<.001$ & $69.4(67.3-71.3)$ & $70.2(69.0-71.4)$ & $71.1(70.2-72.0)$ & $71.9(70.8-72.9)$ & $72.6(71.4-73.7)$ \\
\hline CHF: ACEI/ARB & .39 & $67.3(65.1-69.3)$ & $67.9(66.6-69.2)$ & $68.5(67.5-69.4)$ & $68.9(67.7-70.0)$ & $69.2(67.9-70.4)$ \\
\hline Asthma: Spirometry & .33 & $24.9(22.7-27.3)$ & $24.4(23.0-25.9)$ & $24.0(22.9-25.1)$ & $23.6(22.4-24.9)$ & $23.3(21.9-24.7)$ \\
\hline \multicolumn{7}{|c|}{ Access \& Outcomes $(\mathrm{RIO}<10), \%(95 \% \mathrm{Cl})$} \\
\hline Admissions for ACSC & .04 & $12.0(11.4-12.7)$ & $12.2(11.7-12.8)$ & $12.4(12.0-12.9)$ & $12.6(12.1-13.2)$ & $12.8(12.2-13.4)$ \\
\hline ED visits, low triage & .004 & $19.5(18.7-20.3)$ & $19.0(18.5-19.4)$ & $18.5(18.1-18.8)$ & $18.1(17.7-18.5)$ & $17.8(17.3-18.3)$ \\
\hline \multicolumn{7}{|l|}{ Physician, \% (95\% Cl) } \\
\hline Continuity & $<.001$ & $78.0(77.4-78.5)$ & $78.6(78.2-78.9)$ & $79.1(78.8-79.3)$ & $79.3(79.0-79.7)$ & $79.3(78.9-79.8)$ \\
\hline Comprehensiveness & .03 & $66.5(65.8-67.2)$ & $66.6(66.2-67.0)$ & $66.7(66.3-67.0)$ & $66.7(66.2-67.2)$ & $66.5(66.0-67.1)$ \\
\hline
\end{tabular}

The likelihood of being up-to-date according to guideline requirements for cervical cancer screening decreased with increasing panel size by $5.0 \%$, (from $63.7 \%$ to $58.7 \%)$, or a $7.9 \%$ relative difference $(P<.001)$. Breast and colorectal cancer screening showed a similar but less-pronounced association, with absolute and relative differences from peak to nadir of $3.0 \%$ and $4.6 \%$, respectively for breast $(P<.001)$, and $2.7 \%$ and $5.9 \%$, respectively, for colorectal cancer $(P=.01)$.

Only 1 of the 9 chronic disease indicators reflecting the guidelines for the management of the condition showed an association with panel size. The likelihood of individuals aged 40 years and over with congestive heart failure having an echocardiogram within 1 year of diagnosis increased by $6.1 \%$ (8.1\% relative difference) across the range studied $(P<.001)$. Four medication and 4 screening test indicators showed no significant association.

The rate of non-urgent emergency department visits decreased from 19.5 to 17.4 visits per 100 patients per 2 years, a $10.8 \%$ relative difference (impact of small differences in the decimals not shown), across increasing panel size ranges $(P=.004)$, while the rate of hospitalization for ambulatory-care-sensitive condi- tions increased by 1.25 admissions per 10,000 (relative difference $9.4 \%)$ over the range studied $(P=.04)$.

Continuity, which reflects the proportion of primary care visits made to the practice to which the patient is attached, showed a modest inverted U-shaped relationship with panel size. Patients were less likely to receive primary care services from the practice to which their physician belonged if their physician had smaller or larger panel sizes $(\mathrm{P}<.001)$. The difference between the highest and lowest estimated continuity scores was $2.6 \%$ (relative difference 3.3\%). We found a modest decrease in comprehensiveness, the proportion of 20 standard primary care services rendered, (1.6\% absolute, and $2.4 \%$ relative difference) with increasing panel size $(P=.03)$.

\section{DISCUSSION}

\section{Main Findings}

Within the panel size range studied, increasing panel size was associated with modest decreases in cancer screening, but we found no decrease in chronic disease management indicators. There was a small but notable inverted $\mathrm{U}$ relationship with relational continuity, and 
Panel Size

2,700

3,000

3,300

3,600

$62.7(62.2-63.3)$

$62.4(61.8-63.0)$

$62.1(61.4-62.9)$

$61.9(60.8-62.9)$

$59.5(58.7-60.3)$

$59.2(58.1-60.3)$

$58.9(57.4-60.5)$

$43.0(42.1-43.9)$

$43.2(42.1-44.2)$

$43.5(42.1-44.9)$

$44.0(42.1-45.9)$

\begin{tabular}{lllll}
$72.0(71.6-72.3)$ & $71.9(71.5-72.4)$ & $71.9(71.4-72.4)$ & $71.8(71.2-72.5)$ & $71.8(70.9-72.7)$ \\
$63.6(62.7-64.5)$ & $63.7(62.6-64.8)$ & $63.8(62.4-65.3)$ & $64.0(61.9-65.9)$ & $64.1(61.4-66.6)$ \\
$37.9(36.9-39.0)$ & $37.6(36.3-38.9)$ & $37.2(35.5-38.9)$ & $36.9(34.6-39.2)$ & $36.5(33.6-39.5)$ \\
$86.8(85.3-88.1)$ & $86.6(85.1-88.1)$ & $86.6(84.9-88.2)$ & $86.6(84.5-88.5)$ & $86.6(84.0-88.9)$ \\
$74.1(73.6-74.6)$ & $74.2(73.7-74.7)$ & $74.2(73.6-74.9)$ & $74.3(73.5-75.1)$ & $74.4(73.3-75.4)$ \\
$70.1(69.6-70.7)$ & $70.2(69.5-70.8)$ & $70.2(69.4-71.1)$ & $70.3(69.1-71.4)$ & $70.3(68.8-71.7)$ \\
& & & & \\
$73.2(72.0-74.4)$ & $73.8(72.5-75.1)$ & $74.4(72.8-75.9)$ & $74.9(72.9-76.8)$ & $75.5(72.9-77.8)$ \\
$69.3(67.9-70.6)$ & $69.3(67.8-70.7)$ & $69.3(67.5-71.0)$ & $69.2(66.9-71.4)$ & $69.2(66.3-71.9)$ \\
$23.0(21.5-24.6)$ & $22.8(21.2-24.4)$ & $22.6(20.8-24.4)$ & $22.4(20.3-24.6)$ & $22.2(19.6-25.1)$ \\
& & & & \\
$12.9(12.3-13.5)$ & $13.0(12.4-13.7)$ & $13.1(12.4-13.8)$ & $13.2(12.4-14.0)$ & $13.3(12.3-14.3)$ \\
$17.6(17.1-18.2)$ & $17.5(16.9-18.1)$ & $17.4(16.8-18.1)$ & $17.4(16.6-18.3)$ & $17.4(16.3-18.5)$ \\
$79.1(78.7-79.6)$ & $78.7(78.1-79.2)$ & $78.1(77.4-78.8)$ & $77.4(76.5-78.3)$ & $76.7(75.6-77.9)$ \\
$66.3(65.7-66.9)$ & $66.1(65.4-66.7)$ & $65.7(65.0-66.4)$ & $65.4(64.5-66.3)$ & $65.1(64.0-66.1)$ \\
\hline & & & &
\end{tabular}

a negligible drop in comprehensiveness of care across the panel size range. The likelihood of having a hospitalization related to an ambulatory-care-sensitive condition increased with larger panel sizes, whereas the likelihood of making use of the emergency department for non-urgent issues dropped.

\section{Comparison With Other Studies}

Findings of this study are in keeping with others reporting negative associations between panel size and cancer screening, ${ }^{8,20}$ as well as with studies finding no associations with recommended chronic disease processes of care ${ }^{20}$ and clinical outcome measures. ${ }^{21} \mathrm{~A}$ possible explanation is that cancer-screening interventions are more time consuming because they necessitate a discussion of risks and benefits of screening and often the completion of a maneuver by the physician. Other time-consuming activities such as healthy lifestyle counseling and immunizations ${ }^{8,20}$ have also been found to be negatively associated with higher panel sizes.

The literature shows that primary care physicians carrying larger panel sizes may be more likely to refer complex patients to specialists, who would then be more likely to adhere to guidelines. ${ }^{22}$ Surprisingly, we
3,900

$61.6(60.3-62.9)$

$58.7(56.6-60.7)$

$44.4(42.0-46.9)$

found the likelihood of undergoing an echocardiogram within 1 year of a congestive heart failure diagnosis showed a positive association with panel size. From our data, we are unable to determine whether higher rates of referral to specialists, greater experience and expertise, or both could have contributed to this pattern.

Hospital admissions for ambulatory-care-sensitive conditions, ostensibly an indirect measure of primary care systems capacity to manage chronic conditions such as diabetes, congestive heart failure, and asthma, ${ }^{23}$ increased across the panel size range studied. Estimates for these hospitalizations, however, had wide confidence intervals, and the findings should thus be interpreted with some caution. In contrast, the rate of emergency department visits for non-urgent conditions, often used as an indicator of poor access to primary care services, ${ }^{24,25}$ was negatively associated with increasing panel sizes; patients of physicians with larger panels had fewer emergency department encounters. The majority of studies assessing access have relied on measures of direct contact with the physicians, such as the number of yearly visits, ${ }^{26}$ home visits, ${ }_{1}^{27}$ and consultation times, ${ }^{3,26,28,29}$ and showed consistently lower access associated with panel size. Another study evaluating emergency department visits as we did reported no association with panel size. ${ }^{30}$

We found a negligible decrease in the comprehensiveness of care and small changes in continuity of care across the panel size range we studied. ${ }^{31}$ Continuity appeared optimized in the mid-range, showing a maximum gain of $2.6 \%$ in that range relative to the lowest measure. Since an ongoing and consistent relationship with the same primary care provider or practice over time is associated with better patient outcomes, especially for patients with chronic conditions, this difference may be of clinical relevance. ${ }^{32,33}$

\section{Strengths and Limitations}

Our study estimated the association between panel sizes ranging from 1,200 to 3,900 and a broad spectrum of primary care quality indicators in more than 4,000 primary care physicians using a cross sectional, 
population-based design relying on health administrative data. The study's multiple outcomes, though allowing us a comprehensive assessment of the potential role of panel size, were vulnerable to type I errors. For that reason, statistical significance, especially when weak, should be interpreted with caution. In addition, the precision of some estimates was lower, as reflected by the broader confidence intervals. As a result, it is possible that potentially meaningful differences across panel sizes could not be detected for some measures.

The analyses accounted for several factors potentially confounding the relationship of interest. We controlled for rurality because the limited availability of other health care services in rural areas can lead primary care physicians to take on a broader role in patients' care provision, consuming more of their time. ${ }^{34}$ We accounted for the model in which care was provided because the remuneration structure is known to affect physician behavior ${ }^{35}$ and because team composition can affect the practice's capacity to care for patients. We recognize, however, that many practices that did not receive funding to establish interprofessional teams would likely have included nurses, and that, in exceptional cases, some might have independently hired a complement of other health professionals. These practices would have remained attributed to the non-interprofessional group in the analyses. We accounted for the $\operatorname{sex}^{36-38}$ and age $\mathrm{e}^{39}$ of the physician because these were found to be associated with quality of care in some studies. We used multiple factors to control for patient medical or social complexity, as complex patients require more time per visit and more visits per year. ${ }^{40,41}$ Socioeconomic status and immigration, however, were determined by proxy measures. We also cannot exclude the possibility that some unmeasured and unaccounted-for factor may be contributing to the observed associations.

Importantly, we did not have access to some parameters that could have helped us explain our findings. For example, we didn't know whether physicians with larger panel sizes worked longer hours to accommodate the increased demands of a larger practice. ${ }^{26} \mathrm{We}$ also had no data on physicians' attitudes and behaviors, and have limited information on practice organizational structure and context.

\section{CONCLUSION}

Because the observed differences in quality of care associated with panel size were modest, and especially because all showed apparent gradual changes over the panel size range studied, with no evidence of a threshold or shoulder beyond which quality dropped, our findings do not support policy measures such as thresholds or caps that reduce payments to physicians with large panel sizes.

We postulate that physicians who take on larger patient panels may be able to do so without compromising care quality because some personal or practice characteristics allow them to provide effective and efficient care. Characteristics such as physician communication style, ${ }^{42,43}$ better organizational climate, ${ }_{1}^{44,45}$ and systematic improvements in practice access ${ }^{46}$ are reported to promote efficiency and/or quality. We need to better understand what makes some practices high performing and what factors support greater efficiency. Building on this work, our team is undertaking a survey of Ontario primary care practices to understand their organizational structure and study the relationship of organizational factors with quality measures. Subsequent research should also include practice-based observations and qualitative studies that allow a more in-depth understanding about efficient high-performing practices.

To read or post commentaries in response to this article, see it online at http://www.annfammed.org/content/14/1/26.

Key words: primary health care; workload; quality indicators; panel size

Submitted March 9, 2015; submitted, revised, August 13, 2015; accepted August 19, 2015.

Funding support: All authors had financial support from the Canadian Institutes of Health Research (FRN 102660). This study was supported by the Institute for Clinical Evaluative Sciences (ICES), which is funded by an annual grant from the Ontario Ministry of Health and Long-Term Care (MOHLTC).

Disclaimer: The opinions, results, and conclusions reported in this paper are those of the authors and are independent from the funding sources. The funders had no role in the design or implementation of the study. No endorsement by ICES or the Ontario MOHLTC is intended or should be inferred.

Previous presentations: North American Primary Care Research Group Annual Meeting. December 1-5, 2012, New Orleans, Louisiana; Canadian Association for Health Services and Policy Research (CAHSPR), May 29 - 31, 2012, Montreal, Québec; Trillium Primary Health Care Research Day, June 6, 2012, Toronto, Ontario; Kingston, Ontario, and Institute of Clinical and Evaluative Sciences Program Meeting, February 20, 2013; ,Toronto, Ontario.

Acknowledgments: The authors would like to extend thanks to Monica Hernandez for excellent study coordination, and Alex Kopp and Steven Hawken, senior analysts, for their guidance in the analyses.

Supplementary materials: Available at http://www.AnnFamMed. org/content/14/1/26/suppl/DC1.

\section{References}

1. Hutchison B, Levesque JF, Strumpf E, Coyle N. Primary health care in Canada: systems in motion. Milbank Q. 2011;89(2):256-288.

2. College of Family Physicians of Canada. Best advice: panel size. http://www.cfpc.ca/uploadedFiles/Health_Policy/_PDFs/Final\%20 June\%209\%2011\%20Final\%20Panel\%20Size\%20Best\%20Advice. pdf. Published Sep 2012. Accessed Feb 4, 2015. 
3. Campbell JL, Ramsay J, Green J. Practice size: impact on consultation length, workload, and patient assessment of care. Br J Gen Pract. 2001;51(469):644-650.

4. Butler JR, Calnan MW. List sizes and use of time in general practice. Br Med J (Clin Res Ed). 1987;295(6610):1383-1386.

5. Wranik D, Durier-Copp M. Framework for the design of physician remuneration methods in primary health care. Soc Work Public Health. 2011;26(3):231-259.

6. Armstrong D, Britten N, Grace J. Measuring general practitioner referrals: patient, workload and list size effects. J $R$ Coll Gen Pract. 1988;38(316):494-497.

7. Hogg W, Dahrouge S, Russell G, et al. Health promotion activity in primary care: performance of models and associated factors. Open Med. 2009;3(3):e165-e173.

8. Dahrouge S, Hogg WE, Russell G, et al. Impact of remuneration and organizational factors on completing preventive manoeuvres in primary care practices. CMAJ. 2012;184(2):E135-E143.

9. Russell GM, Dahrouge S, Hogg W, Geneau R, Muldoon L, Tuna M. Managing chronic disease in ontario primary care: the impact of organizational factors. Ann Fam Med. 2009;7(4):309-318.

10. Kralj B. Measuring rurality - RIO2008_BASIC: methodology and results. https://www.oma.org/Resources/Documents/2008RIO-Full TechnicalPaper.pdf. Published Feb 2, 2009. Accessed Apr 14, 2014.

11. Krieger N, Chen JT, Waterman PD, Soobader MJ, Subramanian SV, Carson R. Geocoding and monitoring of US socioeconomic inequalities in mortality and cancer incidence: does the choice of areabased measure and geographic level matter?: the Public Health Disparities Geocoding Project. Am J Epidemiol. 2002;156(5):471-482.

12. Mustard CA, Derksen S, Berthelot JM, Wolfson M. Assessing ecologic proxies for household income: a comparison of household and neighbourhood level income measures in the study of population health status. Health Place. 1999;5(2):157-171.

13. Milan A. Migration: interprovincial, 2008/2009. http://www.statcan.gc.ca/pub/91-209-x/2011001/article/11514-eng.htm. Published Sep 20, 2011. Accessed Jan 28, 2014.

14. The Johns Hopkins Adjusted Clinical Groups (ACG) Case-Mix System. http://acg.jhsph.org/. 2008. Accessed Feb 24, 2014.

15. Hux JE, Ivis F, Flintoft V, Bica A. Diabetes in Ontario: determination of prevalence and incidence using a validated administrative data algorithm. Diabetes Care. 2002;25(3):512-516.

16. Jonsson A, Edner M, Alehagen $U$, Dahlström $U$. Heart failure registry: a valuable tool for improving the management of patients with heart failure. Eur J Heart Fail. 2010;12(1):25-31.

17. To T, Dell S, Dick PT, et al. Case verification of children with asthma in Ontario. Pediatr Allergy Immunol. 2006;17(1):69-76.

18. Stone CJ, Koo CY. Additive splines in statistics. In: Proceedings of the Statistical Computing Section. Alexandria, VA: American Statistical Association; 1985. 45-48.

19. Harrell F. SAS macros for assisting with survival and risk analysis, and some SAS procedures useful for multivariable modeling. http:// biostat.mc.vanderbilt.edu/wiki/Main/SasMacros. Published Jan 23, 2004. Accessed May 12, 2013.

20. Stefos T, Burgess JF Jr, Mayo-Smith MF, et al. The effect of physician panel size on health care outcomes. Health Serv Manage Res. 2011;24(2):96-105.

21. Hansen LJ, Olivarius NdeF, Siersma V, Andersen JS. Doctors' characteristics do not predict long-term glycaemic control in type 2 diabetic patients. Br J Gen Pract. 2003;53(486):47-49.

22. Boom NK, Lee DS, Tu JV. Comparison of processes of care and clinical outcomes for patients newly hospitalized for heart failure attended by different physician specialists. Am Heart J. 2012;163(2):252-259.

23. Ansari Z, Laditka JN, Laditka SB. Access to health care and hospitalization for ambulatory care sensitive conditions. Med Care Res Rev. 2006;63(6):719-741.
24. Baker R, Bankart MJ, Rashid A, et al. Characteristics of general practices associated with emergency-department attendance rates: a cross-sectional study. BMJ Qual Saf. 2011;20(11):953-958.

25. Petersen LA, Burstin HR, O'Neil AC, Orav EJ, Brennan TA. Nonurgent emergency department visits: the effect of having a regular doctor. Med Care. 1998;36(8):1249-1255.

26. Wilkin $\mathrm{D}$, Metcalfe $\mathrm{DH}$. List size and patient contact in general medical practice. Br Med J (Clin Res Ed). 1984;289(6457):1501-1505.

27. Whynes DK, Baines DL. Explaining variations in the frequency of night visits in general practice. Fam Pract. 1996;13(2):174-178.

28. Calnan M, Groenewegen PP, Hutten J. Professional reimbursement and management of time in general practice. An international comparison. Soc Sci Med. 1992;35(2):209-216.

29. van den Berg MJ, de Bakker DH, Westert GP, van der Zee J, Groenewegen PP. Do list size and remuneration affect GPs' decisions about how they provide consultations? BMC Health Serv Res. 2009;9:39.

30. McKee CM, Gleadhill DN, Watson JD. Accident and emergency attendance rates: variation among patients from different general practices. Br J Gen Pract. 1990;40(333):150-153.

31. Mohr DC, Young GJ. Slack resources and quality of primary care. Med Care. 2012;50(3):203-209.

32. Hollander MJ, Kadlec $\mathrm{H}$, Hamdi R, Tessaro A. Increasing value for money in the Canadian healthcare system: new findings on the contribution of primary care services. Healthc Q. 2009;12(4):32-44.

33. Atlas SJ, Grant RW, Ferris TG, Chang Y, Barry MJ. Patient-physician connectedness and quality of primary care. Ann Intern Med. 2009; 150(5):325-335.

34. Kralj B. Measuring "rurality" for purposes of health-care planning: an empirical measure for Ontario. Ont Med Rev. 2000;67(9):33-52.

35. Altschuler J, Margolius D, Bodenheimer T, Grumbach K. Estimating a reasonable patient panel size for primary care physicians with team-based task delegation. Ann Fam Med. 2012;10(5):396-400.

36. Reid RO, Friedberg MW, Adams JL, McGlynn EA, Mehrotra A. Associations between physician characteristics and quality of care. Arch Intern Med. 2010;170(16):1442-1449.

37. Journath $G$, Hellénius $M L$, Carlsson AC, Wändell PE, Nilsson PM; Hyper-Q and Eko Study Groups, Sweden. Physicians' gender is associated with risk factor control in patients on antihypertensive and lipid lowering treatment. Blood Press. 2010;19(4):240-248.

38. Kim C, McEwen LN, Gerzoff RB, et al. Is physician gender associated with the quality of diabetes care? Diabetes Care. 2005;28(7): 1594-1598.

39. Choudhry NK, Fletcher RH, Soumerai SB. Systematic review: the relationship between clinical experience and quality of health care. Ann Intern Med. 2005;142(4):260-273.

40. Carlisle R, Avery AJ, Marsh P. Primary care teams work harder in deprived areas. J Public Health Med. 2002;24(1):43-48.

41. Potts B, Adams R, Spadin M. Sustaining primary care practice: a model to calculate disease burden and adjust panel size. Perm J. 2011;15(1):53-56.

42. Dobscha SK, Leibowitz RQ, Flores JA, Doak M, Gerrity MS. Primary care provider preferences for working with a collaborative support team. Implement Sci. 2007;2:16.

43. Groenewegen PP, Hutten JB. Workload and job satisfaction among general practitioners: a review of the literature. Soc Sci Med. 1991; 32(10):1111-1119.

44. Benzer JK, Young G, Stolzmann K, et al. The relationship between organizational climate and quality of chronic disease management. Health Serv Res. 2011;46(3):691-711.

45. Mohr DC, Benzer JK, Young GJ. Provider workload and quality of care in primary care settings: moderating role of relational climate. Med Care. 2013;51(1):108-114.

46. Conrad D, Fishman P, Grembowski $D$, et al. Access intervention in an integrated, prepaid group practice: effects on primary care physician productivity. Health Serv Res. 2008:43(5 Pt 2):1888-1905. 